\title{
Produção e qualidade de azevém-anual submetido a adubação nitrogenada sob pastejo por cordeiros
}

\author{
Luiz Giovani de Pellegrini ${ }^{1}$, Alda Lúcia Gomes Monteiro ${ }^{2}$, Mikael Neumann ${ }^{3}$, Aníbal de \\ Moraes $^{4}$, Ana Carolina Ribeiro Sanquetta de Pellegrin ${ }^{5}$, Sebastião Brasil Campos Lustosa ${ }^{6}$ \\ ${ }^{1}$ Doutorando da Universidade Federal do Paraná na Área de Produção Vegetal - Sistemas Integrados de Produção. \\ 2 Departamento de Zootecnia da UFPR - Curitiba, PR. \\ 3 Departamento de Medicina Veterinária da UNICENTRO - Guarapuava, PR \\ ${ }^{4}$ Departamento de Fitotecnia e Fitossanitarismo da UFPR - Curitiba, PR. \\ 5 Curso de Medicina Veterinária da UNICENTRO - Guarapuava, PR \\ ${ }^{6}$ Departamento de Agronomia da UNICENTRO - Guarapuava, PR.
}

RESUMO - O objetivo neste trabalho foi verificar como a adubação nitrogenada pode afetar a produção e a qualidade da massa de forragem em pastagem de azevém-anual (Lolium multiflorum Lam.) sob lotação contínua de cordeiros de corte. O azevém foi implantado em 6 de junho de 2006, em sistema de plantio direto com densidade de semeadura de $45 \mathrm{~kg}$ de sementes/ha. A adubação de base foi de $300 \mathrm{~kg} / \mathrm{ha}$, sem nitrogênio, com $60 \mathrm{~kg} / \mathrm{ha} \mathrm{P}_{2} \mathrm{O}_{5}$ e $60 \mathrm{~kg} / \mathrm{ha} \mathrm{K}_{2} \mathrm{O}$. As adubações corresponderam a quatro doses de nitrogênio $(\mathrm{N})$ na forma de ureia $(45 \%$ de $\mathrm{N})$ em aplicação de cobertura após 35 dias do plantio: 0; 75; 150; ou 225 kg/ha de N. O período de avaliação foi de 84 dias. Para cada kg de nitrogênio aplicado na pastagem de azevém, verificaram-se aumentos lineares de $2,82 \mathrm{~kg} / \mathrm{ha}$ de massa de forragem, 1,28 kg/ha de massa seca de folhas verdes, 2,47 perfilhos $/ \mathrm{m}^{2}$ e $15,84 \mathrm{~kg} / \mathrm{ha}$ de massa de forragem total. As doses de nitrogênio aplicadas não influenciaram os teores de proteína bruta (21,21\%), fibra detergente ácido (25,90\%) e fibra detergente neutro $(54,93 \%)$ da forragem colhida por meio da simulação do pastejo. O aumento nas doses de nitrogênio interferem positivamente na taxa de acúmulo, o que proporciona maior massa de forragem total.

Palavras-chave: cordeiros, perfilhos, produção de matéria seca, taxa de acúmulo, ureia

\section{Production and quality of annual ryegrass submitted to nitrogen fertilization under grazing by lambs}

\begin{abstract}
The aim of this work was to evaluate how nitrogen fertilization can affect forage mass production and quality on annual Italian ryegrass (Lolium multiflorum Lam.) pasture under continuous stocking of beef lambs. Ryegrass was established on June $6^{\text {th }}$, 2006, on no-tillage cropping system with seed density of $45 \mathrm{~kg}$ seeds/ha. Base fertilization was $300 \mathrm{~kg} / \mathrm{ha}$ without $\mathrm{N}$, with $60 \mathrm{~kg} / \mathrm{ha} \mathrm{P}_{2} \mathrm{O}_{5}$ and $60 \mathrm{~kg} / \mathrm{ha} \mathrm{K}_{2} \mathrm{O}$. Fertilization consisted on four doses of nitrogen $(\mathrm{N})$ using urea fertilizer (45\% de N) in covering application 35 days after seeding: 0; 75; 150; or $225 \mathrm{~kg} / \mathrm{ha}$ N. Periods of evaluations lasted 84 days. For each $\mathrm{kg}$ of nitrogen applied on ryegrass pasture, it was observed linear increases of $2.82 \mathrm{~kg} / \mathrm{ha}$ of forage mass, $1.28 \mathrm{~kg} / \mathrm{ha}$ of green leaf dry mass, 2.47 tillers $/ \mathrm{m}^{2}$ and $15.84 \mathrm{~kg} / \mathrm{ha}$ of total forage mass. Doses of applied nitrogen did not affect crude protein contents (21.21\%), acid detergent fiber (25.90\%) and neutral detergent fiber (54.93\%) of forage harvested through grazing simulation. The increase on nitrogen doses interfere positively in the accumulation rate, providing greater total forage mass.
\end{abstract}

Key Words: accumulation rate, dry matter production, lambs, tiller, urea

\section{Introdução}

Recentemente com a transformação do panorama agropecuário, as pastagens cultivadas de inverno passaram a ter papel fundamental nos diferentes sistemas de produção, tendo em vista que o objetivo dos produtores é a busca da intensificação do uso da terra e o desenvolvimento de sistemas de produção mais estáveis (Assmann et al., 2004).
Neste contexto, o azevém comum (Lolium multiflorum Lam.) é uma das espécies hibernais apropriadas, devido à capacidade de adaptação às diferentes condições climáticas, à capacidade de cultivo isolado ou consorciado, às características quanti-qualitativas e por responder linearmente às doses de adubação nitrogenada (Alvim \& Moojen, 1984).

Desde o início dos estudos sobre a utilização do N como ferramenta de manejo, Mott et al. (1970) e, mais 
recentemente, Morón (1994) e Assmann et al. (2004) referem a produtividade das pastagens à quantidade de nitrogênio disponível à planta, pois este, segundo os autores, é o nutriente mais limitante ao crescimento destas.

A quantidade de biomassa produzida em uma comunidade de plantas é determinada pelo acúmulo de carbono, sendo este o principal constituinte dos tecidos vegetais, que ocorre por meio do processo fotossintético, sendo influenciado diretamente pelo teor de $\mathrm{N}$ presente nos tecidos da planta (Gastal et al., 1992; Lemaire \& Chapman, 1996). Ainda, o N interfere na morfogênese das gramíneas, principalmente a taxa de expansão foliar e de perfilhamento (Gastal et al., 1992; Lemaire \& Gastal, 1997). Ainda, Manzanti \& Lemaire (1994) relatam que a fertilização nitrogenada influencia a estrutura da pastagem, uma vez que ela modifica a densidade dos perfilhos e a distribuição vertical da forragem.

Em relação ao teor de proteína bruta, é consenso na literatura que, à medida que se elevam as doses de $\mathrm{N}$, aumenta-se o teor de proteína bruta (Lupatini et al., 1998), mas Whitehead (1995) salienta que, para que ocorra o aumento na fração proteica na planta, condições de umidade e de outros nutrientes não podem ser limitantes.

Informações ainda são escassas quando se trabalha com pastagem de azevém submetida a diferentes doses de nitrogênio manejada com ovinos, principalmente quando se refere à capacidade de suporte nas distintas regiões fisiográficas, bem como ao potencial de produção em kg de cordeiro. Assim, o objetivo deste trabalho foi verificar de que maneira a adubação nitrogenada, em pastagem de azevém sob lotação contínua de cordeiros para carne, pode afetar a produção e a qualidade da massa de forragem.

\section{Material e Métodos}

O experimento foi conduzido nas instalações do Núcleo de Produção Animal (NUPRAN) do Setor de Ciências Agrárias e Ambientais da Universidade Estadual do CentroOeste (UNICENTRO), em Guarapuava-PR, no período de $1^{0}$ de junho de 2006 a 12 de novembro de 2006.

O clima da região é o Cfb (Subtropical mesotérmico úmido), sem estação seca, com verões frescos e inverno moderado, conforme a classificação de Köppen, em altitude de aproximadamente $1300 \mathrm{~m}$, precipitação média anual de $1944 \mathrm{~mm}$, temperatura média mínima anual de $12,7^{\circ} \mathrm{C}$, temperatura média máxima anual de $23,5^{\circ} \mathrm{C}$ e umidade relativa do ar de 77,9\%. O solo da área experimental, classificado como Latossolo Bruno Aluminoférrico Típico (Embrapa, 2006), em julho de 2006, apresentou as seguintes características químicas(perfilde0a20cm): $\mathrm{pHCaCl}_{20,01 \mathrm{M}}$ :4,7;
$\mathrm{P}: 1,1 \mathrm{mgdm}^{3-} ; \mathrm{K}^{+}: 0,2 \mathrm{cmol}_{\mathrm{C}} \mathrm{dm}^{3-} ; \mathrm{MO}: 2,62 \% ; \mathrm{Al}^{3+}: 0,0 \mathrm{cmol}_{\mathrm{C}} \mathrm{dm}^{3-}$; $\mathrm{H}^{+}+\mathrm{Al}^{3+}: 5,2 \mathrm{cmol}_{\mathrm{C}} \mathrm{dm}^{3-} ; \mathrm{Ca}^{2+}: 5,0 \mathrm{cmol}_{C} \mathrm{dm}^{3-} ; \mathrm{Mg}^{2+}: 5,0 \mathrm{cmol}_{C} \mathrm{dm}^{3-}$ e saturação de bases: $67,3 \%$.

A pastagem de azevém (Lolium multiflorum Lam.) foi implantada em 06 de junho de 2006, em sistema de semeadura direta, após aplicação do herbicida gliphosate (360 g/L). Na implantação do azevém, o espaçamento entre linhas foi de $15 \mathrm{~cm}$, com profundidade de semeadura de 1 a $3 \mathrm{~cm}$ e densidade de $45 \mathrm{~kg}$ de sementes/ha.

As adubações corresponderam a quatro doses de nitrogênio (N), na forma de ureia ( $45 \%$ de N) sendo: $0 \mathrm{~kg} / \mathrm{ha}$ de N; 75 kg/ha de N; 150 kg/ha de N; e 225 kg/ha de N. Foi utilizada adubação de base, no momento da semeadura da pastagem, de $0 \mathrm{~kg} \mathrm{~N}, 60 \mathrm{~kg} / \mathrm{ha} \mathrm{P}_{2} \mathrm{O}_{5}$ e $60 \mathrm{~kg} / \mathrm{ha} \mathrm{K}_{2} \mathrm{O}$, conforme Comissão ... (1995). Após 35 dias da semeadura (11 de julho de 2006), foi efetuada aplicação única da adubação nitrogenada em cobertura na forma de ureia, o que corresponde ao início do perfilhamento das plântulas.

A área total do experimento foi de 3,1 ha, tendo 0,5 ha sido destinado à manutenção de animais reguladores; 2,6 ha foram subdivididos em três blocos de 0,88 ha cada, sendo cada bloco dividido em 4 piquetes (unidade experimental) com $0,22 \mathrm{ha}$. O delineamento experimental foi o de blocos ao acaso, composto por quatro doses de $\mathrm{N}$, com três repetições (piquetes).

O período experimental foi de 90 dias, sendo 6 dias de adaptação dos animais à dieta e às instalações e, em seguida, quatro períodos de 21 dias de avaliação, procurando-se acompanhar os estádios de desenvolvi-mento do azevém (primeiro período, 20/8/2006 a 9/9/2006 - estádio vegetativo; segundo período, 10/09/2006 a 30/09/2006 - estádio vegetativo; terceiro período, 1/10/2006 a 21/10/2006 - estádio pré-florescimento; e quarto período, 22/10/2006 a 11/11/2006 - estádio florescimento). O curto período de adaptação dos animais justifica-se pelo fato de que eles já estavam em pastejo em azevém nas propriedades de origem.

Foram utilizados 72 cordeiros-teste desmamados com idade média de dois meses e peso vivo inicial de $24,7 \mathrm{~kg} \pm 0,57 \mathrm{~kg}$. Os animais foram distribuídos aleatoriamente nas unidades experimentais de acordo com peso, sexo e raça. Cada um dos doze lotes de seis animais constituiu-se de dois machos castrados, dois machos inteiros e duas fêmeas. Os animais utilizados como reguladores foram provenientes de rebanhos cruzados de propriedades próximas do local de execução do experimento. Todos os animais foram vermifugados com ivermectina e pesados em jejum de sólidos de 14 horas, antes de entrar na área experimental.

Os animais foram mantidos em azevém em sistema de lotação contínua, em piquetes de 0,22 ha cada, com lotação 
variável ajustada pela técnica put-and-take (Moot \& Lucas, 1952), utilizando-se seis animais testes e número variável de reguladores por piquetes, com o objetivo de manter a altura do pasto entre 14 e $15 \mathrm{~cm}$, seguindo recomendações de Freitas (2003). Assim, os ajustes da lotação foram feitos periodicamente em intervalos de três dias, considerando a metodologia descrita por Carvalho et al. (2001).

Para alcançar o manejo pretendido, utilizaram-se, além dos 72 animais-teste, 130 animais reguladores que apresentavam mesma idade média e mesmo peso vivo, com o objetivo de não alterar o comportamento de pastejo.

A massa de forragem foi determinada a cada 21 dias por meio da técnica de dupla amostragem (Gardner, 1986), com corte rente ao solo de duas amostras $\left(0,25 \mathrm{~m}^{2}\right)$ para 15 avaliações visuais, por piquete. A forragem proveniente das amostras cortadas foi homogeneizada e, posteriormente, foram formadas duas amostras compostas. Uma amostra foi utilizada para a determinação da composição botânica, sendo separadas manualmente as partes da planta: folha, colmo, espiga e material senescente. Estes foram secos em estufa com ar forçado a $65^{\circ} \mathrm{C}$ por 72 horas para estimativa do teor de matéria seca. A outra amostra composta também foi pesada e colocada na estufa de ar forçado a $65^{\circ} \mathrm{C}$ por 72 horas para determinação do teor de matéria seca.

A altura do pasto referiu-se à altura da superfície das lâminas foliares verdes, estimada a partir do nível do solo (Hodgson, 1990), medida com o auxílio de um bastão graduado denominado sward stick(Bircham, 1981). A leitura da altura da pastagem foi realizada a cada três dias em 100 pontos aleatórios por cada unidade experimental (piquete).

O número de perfilhos foi avaliado nos quatro períodos de utilização da pastagem, por meio de quatro cortes rentes ao solo por piquete, com o auxílio de um quadrado com área conhecida $(0,25 \times 0,25)$. Posterior aos cortes, as amostras foram encaminhadas ao Laboratório NUPRAN da UNICENTRO para contagem manual dos perfilhos. Determinou-se, ainda, a densidade de forragem, dividindose a massa desta pela altura da pastagem, sendo expressa em $\mathrm{kg} / \mathrm{ha} / \mathrm{cm}$ de matéria seca.

A taxa de acúmulo foi avaliada a cada 21 dias com o uso de duas gaiolas de exclusão ao pastejo por unidade experimental, por uso da técnica do triplo emparelhamento (Moraes et al., 1990) e estimada pela equação descrita por Campbell (1966): $T j=\frac{G i-F g(i-1)}{n}$, em que: $\mathrm{Tj}=$ taxa de acúmulo de MS diária/ha, no período j; Gi = média da quantidade de MS/ha dentro da gaiola na avaliação i; Fg = média da quantidade de MS/ha no ponto na avaliação i-1; n = número de dias do período j.
A massa de forragem parcial foi obtida por meio da multiplicação da taxa de acúmulo média do período pelo número de dias do período. Já a produção total de massa de forragem da pastagem foi obtida por meio do somatório das taxas de acúmulo de massa de forragem do período experimental mais a massa de forragem presente na entrada dos animais.

Com a observação do hábito de pastejo e da preferência dos animais, foi coletada manualmente amostra (hand plucking) de aproximadamente $0,500 \mathrm{~kg}$ de pasto por unidade experimental (Burns et al., 1989). Posterior à coleta, estas amostras foram pesadas e secas em estufa de ar forçado a $65^{\circ} \mathrm{C}$ por 72 horas. Posteriormente analisou-se a proteína bruta conforme AOAC (1995), fibra insolúvel em detergente neutro e fibra insolúvel em detergente ácido, de acordo com Van Soest et al. (1991).

Os dados coletados para cada variável foram submetidos a análise de variância a 5\% de significância, por meio do proc glm, e os resultados significativos foram submetidos a análise de variância (proc reg); realizou-se ainda a correlação (proc var) entre as variáveis (SAS, 1997).

A análise de cada variável seguiu o modelo estatístico: $\mathrm{Y}_{\mathrm{ijk}}=\mu+\mathrm{N}_{\mathrm{i}}+\mathrm{B}_{\mathrm{j}}+\mathrm{R}_{\mathrm{l}}(\mathrm{N} * \mathrm{~B})_{\mathrm{ij}}+\mathrm{P}_{\mathrm{k}}+(\mathrm{N} * \mathrm{P})_{\mathrm{ik}}+\mathrm{E}_{\mathrm{ijkl}}$; em que: $\mathrm{Y}_{\mathrm{ijk}}=$ variáveis-dependentes; $\mu=$ média geral de todas as observações; $\mathrm{N}_{\mathrm{i}}=$ efeito da dose de nitrogênio ( $\mathrm{N}$ ) de ordem “i”, sendo 1 = dose $0 \mathrm{~kg} / \mathrm{h}$ a de $\mathrm{N}, 2$ = dose $75 \mathrm{~kg} / \mathrm{h}$ a de $\mathrm{N}$, 3 = dose $150 \mathrm{~kg} /$ ha de $\mathrm{Ne} 4$ = dose $225 \mathrm{~kg} /$ ha de $\mathrm{N}$; $\mathrm{B}_{\mathrm{j}}=$ efeito do bloco de ordem “j”, sendo 1 = bloco 1,2 = bloco 2 e 3 = bloco 3; $\mathrm{R}_{1}(\mathrm{~N} * \mathrm{~B})_{\mathrm{ij}}=$ efeito aleatório baseado na repetição dentro da combinação $\left(\mathrm{N}^{*} \mathrm{~B}\right)_{\mathrm{ij}}\left(\right.$ Erro a); $\mathrm{P}_{\mathrm{k}}=$ efeito do período de pastejo de ordem “ $k$ ”, sendo 1 = primeiro período, 2 = segundo período; 3 = terceiro período e $4=$ quarto período; $\left(\mathrm{N}^{*} \mathrm{P}\right)_{\mathrm{ik}}=$ efeito da interação entre a i-ésima dose de $\mathrm{N}$ com o k-ésimo período de pastejo; $\mathrm{E}_{\mathrm{ijk}}=$ efeito aleatório residual (Erro b).

\section{Resultados e Discussão}

Não houve interação $(\mathrm{P}>0,05)$ dose de nitrogênio $\times$ período de utilização da pastagem para massa de forragem, massa de folhas verdes secas, número de perfilhos, taxa de acúmulo, massa de forragem parcial, produção total de massa de forragem, relação folha/colmo, componentes da planta e teores de proteína bruta, fibra detergente ácido e fibra detergente neutro.

A altura da pastagem foi manipulada constantemente por meio do controle da carga animal e, portanto, não apresentou diferença entre as doses de $\mathrm{N}$, com valor de $17,7 \mathrm{~cm} \pm 1,1 \mathrm{~cm}$. 
Em relação à massa de forragem da pastagem de azevém, observa-se efeito significativo $(\mathrm{P}<0,05)$ pelo comportamento linear crescente de 28,22 kg/ha de MS para cada $10 \mathrm{~kg}$ de $\mathrm{N}$ aplicado na pastagem (Figura 1a). Entre as doses de nitrogênio, os valores encontrados foram de 1837,4; 2103,5; 2084,0 e $2549,4 \mathrm{~kg} / \mathrm{ha}$ de MS, respectivamente para as doses 0, 75, 150 e $225 \mathrm{~kg} /$ ha de N. A utilização de N nas doses de $0,75,150$ e $225 \mathrm{~kg}$ resultou, respectivamente, em massas de forragem 14,5; 13,4; e 38,7\% superiores à não-utilização de nitrogênio.

As massas de forragem foram superiores às encontradas por Freitas (2003), que também trabalhou em pasto de azevém sob diferentes doses de nitrogênio, sob lotação contínua de ovinos, e obteve 2507,0; 1999,0; 1802,0; e $1450,0 \mathrm{~kg} / \mathrm{ha}$ de MS para os tratamentos 325, 175, 100 e $25 \mathrm{~kg} / \mathrm{ha}$ de $\mathrm{N}$, respectivamente.

Diante dos resultados observados neste trabalho e o que se encontra na literatura (Soares \& Restle, 2002; Freitas, 2003; Santos et al., 2009), verifica-se que o nitrogênio é capaz de proporcionar aumentos nos rendimentos na massa de forragem produzida. Entretanto, nem sempre estes dados se assemelham. Mesmo que o nitrogênio seja
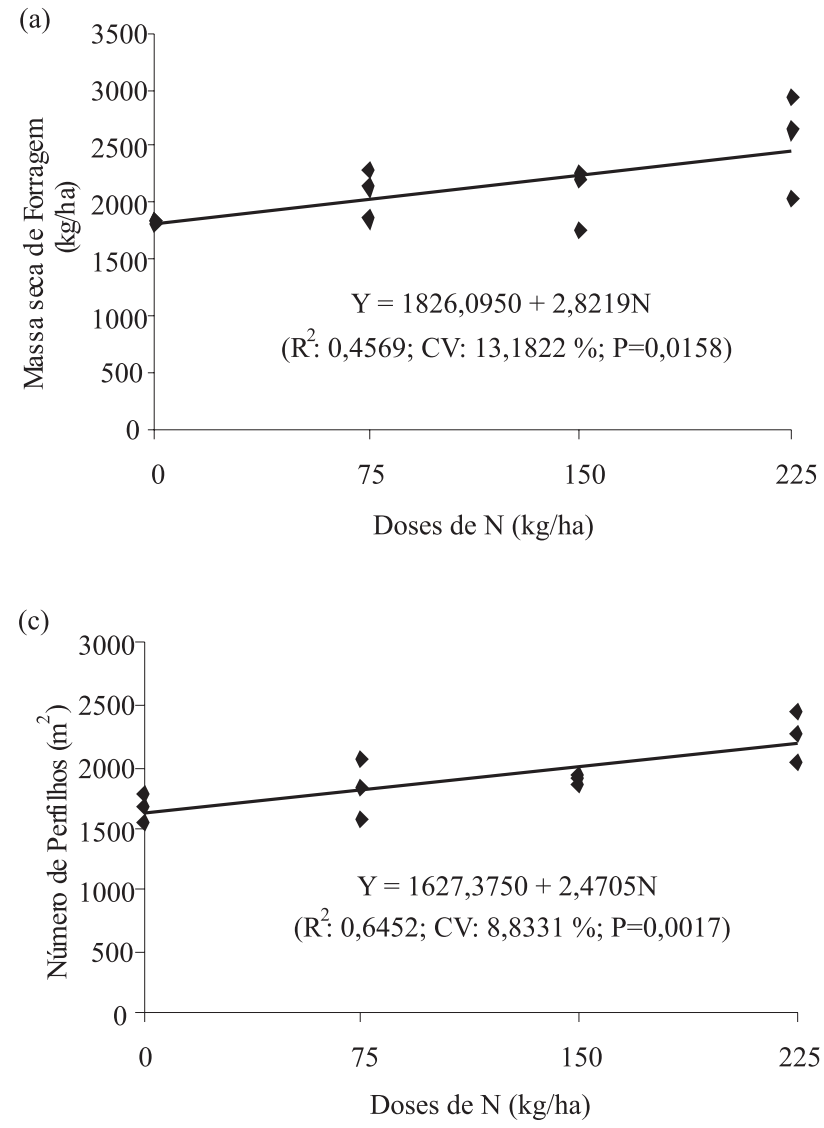

capaz de aumentar o rendimento da massa de forragem, segundo Alvim \& Moojen (1984), deve-se considerar que as diferenças existentes nas produções de massa de forragem ocorrem devido aos fatores climáticos e de solo, manejo, tipo e método de aplicação e até de linhagens de plantas que são selecionadas e adaptadas ao local. Ainda, de acordo com Lupatini et al. (1998), as diferenças encontradas em relação à massa de forragem produzida podem ocorrer em função do parcelamento do nitrogênio, da fonte de nitrogênio, bem como da influência do animal na dinâmica da pastagem e no ciclo do nitrogênio nesse sistema.

Aumentos obtidos na biomassa de forragem são justificados com a afirmação de Lemaire (1991) de que o aumento é a interação entre o modelo morfogênico, que representa a demanda de assimilados (carbono e nitrogênio) para crescimento, e o modelo trófico que representa a oferta (fotossíntese) destes assimilados. Lemaire \& Agnusdei (1999) afirmaram que, quando os assimilados (carbono e nitrogênio) suprem a demanda para crescimento da folha, a planta passa a aumentar o número de meristemas ativos, aumentando assim a densidade de perfilhos e mantendo o crescimento das folhas, até mesmo no perfilho principal.

(b)

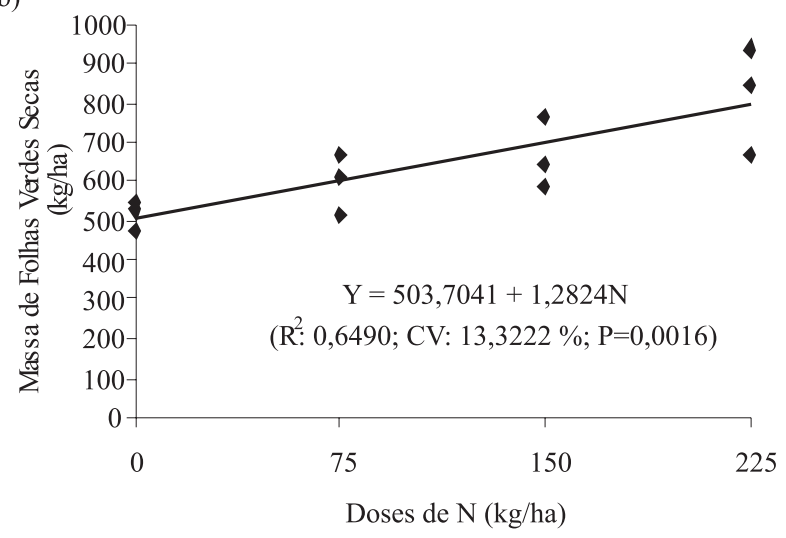

(d)

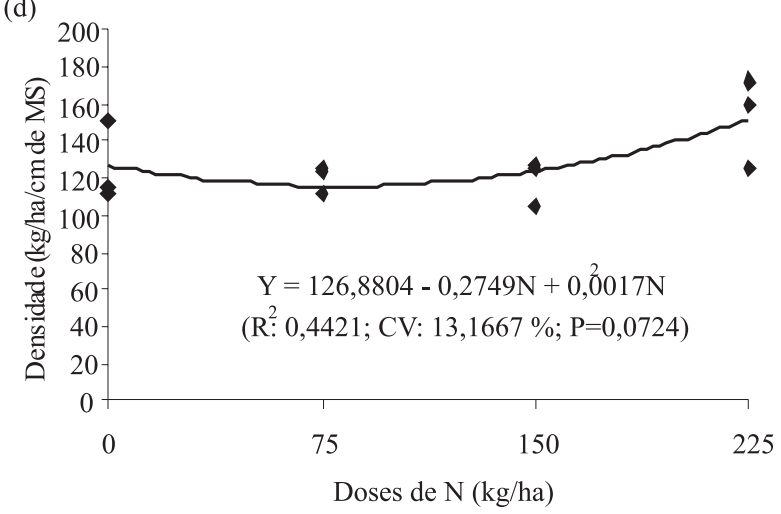

Figura 1 - Massa de forragem, massa de folhas verdes secas, número de perfilhos e densidade de forragem de uma pastagem de azevém sob lotação contínua de cordeiros e adubada com nitrogênio. 
Esse fato deve ter ocorrido, já que, com o aumento na fertilização nitrogenada, foram obtidos aumentos na massa de forragem produzida, bem como aumento no número de perfilhos (Figura 1c). A massa de forragem e o número de perfilhos são dependentes da quantidade de folhas (Figura 1b), que determinam a quantidade de radiação solar interceptada pela cultura e, consequentemente, a quantidade de biomassa produzida (Montheith, 1977), em função do aumento da capacidade fotossintética.

A massa de folhas verdes secas da pastagem de azevém também apresentou comportamento linear crescente de $1,2 \mathrm{~kg} / \mathrm{ha}$ de MS para cada kg de $\mathrm{N}$ aplicado na pastagem; os valores encontrados para massa de folhas verdes foram de 515,0 a 814,6 kg/ha de MS para a dose 0 e $225 \mathrm{~kg} / \mathrm{ha}$ de $\mathrm{N}$, respectivamente (Figura 1b), o que caracterizou a participação de $29 \%$ do componente folhas na massa de forragem, na média das doses de nitrogênio aplicadas (Figura 5b). Roman et al. (2007) encontraram variação de 715,3 a 981,5 kg/ha de MS de massa de folhas verdes secas, o que representou participação média de $62,9 \%$ do componente folhas na estrutura da pastagem, valor bastante superior ao obtido. A diferença justifica-se pelo fato de que esse autor testou diferentes massas de forragem no manejo da pastagem, ao passo que, neste trabalho, o manejo adotado foi a manutenção da altura do pasto.

A manutenção da massa de forragem com alta participação de lâminas foliares é desejável no manejo da pastagem, visto que desempenham papel importante na ecologia de sistemas pastoris, pois produzem assimilados necessários para o crescimento e manutenção da planta, além de servir como fonte de alimento para organismos heterotróficos, incluindo ruminantes (Pontes et al., 2003; Roman et al. (2007).

O número de perfilhos cresceu linearmente $(\mathrm{P}<0,05)$ com o aumento da adubação nitrogenada (Figura 1c), de modo que, para cada kg/ha de $\mathrm{N}$ aplicado, 2,5 novos perfilhos foram observados na estrutura da pastagem.

Mazzanti et al. (1994) afirmaram que o efeito do nitrogênio no número de perfilhos é positivo. Esse efeito depende da taxa de aparecimento de folhas, uma vez que cada folha traz consigo uma gema axilar que poderá desenvolver-se em novo perfilho, dependendo das condições. Neste experimento, mesmo a pastagem sendo manejada à mesma altura, obteve-se maior massa e porcentagem de folhas verdes secas (Figuras $1 \mathrm{~b}$ e $6 \mathrm{~b}$ ) com o aumento da dose de nitrogênio, o que proporcionou maior superfície fotossinteticamente ativa e maior aporte nutricional, resultando em maior número de perfilhos $/ \mathrm{m}^{2}$.

Influência positiva do nitrogênio sobre o número de perfilhos também foi encontrado por Garcez Neto et al. (2002).
De acordo com esses autores, o aumento no número de perfilhos se deve à taxa de aparecimento de folha, que constitui importante determinante na taxa potencial de produção de gemas para a geração de novos perfilhos. As gemas desenvolverão perfilhos em função da interação de vários outros fatores, como luz e nutrientes, como o nitrogênio.

Lustosa (2002) relacionou a produção de massa de forragem por área com o número de perfilhos na pastagem, o que também pode ser observado neste trabalho; ou seja, o aumento no número de perfilhos foi acompanhado pelo aumento na produção de massa de forragem (Figuras 1a, 3b e 4).

Verifica-se que, no primeiro e no segundo períodos de avaliações (Figura 2c), o número de perfilhos foi maior devido à formação do aparato foliar, sendo que a acumulação de forragem não havia limitado a entrada de luz na base do dossel vegetativo. O potencial de perfilhamento é determinado pela velocidade de emissão de novas folhas, sendo que cada folha formada corresponde à geração de uma ou mais gemas axilares (Nabinger, 1996). A não ativação das gemas a partir do terceiro período não é apenas devido à baixa quantidade da luz que ao atravessar o perfil vegetal chega à base das hastes, mas, sobretudo, à qualidade dessa luz, ou seja, a relação vermelho/vermelho-distante (Frank \& Hofman, 1994). Assim, quanto maior o número de perfilhos, maior é a quantidade de gemas que permanecem "inativas" (Lustosa, 2002).

A densidade de forragem da pastagem diminuiu de forma quadrática frente às doses de nitrogênio, com ponto de mínima aos $80,85 \mathrm{~kg} / \mathrm{ha}$ de $\mathrm{N}$ (Figura 1d). Este comportamento demonstra que mesmo as alturas semelhantes condicionam massas de forragem diferentes, sugerindo o efeito do $\mathrm{N}$ na densidade de forragem. A densidade de forragem e altura média da pastagem mantiveram correlação negativa $(r=-0,67)$, confirmando as observações de Hodgson (1990) e Lupatini (1996), de que normalmente a densidade tem relação inversa com a altura da pastagem.

O manejo de pastagens baseado somente no parâmetro altura se torna muito difícil, segundo Lupatini (1996), pois há grande diferença na densidade de forragem. O presente experimento reforça esta afirmação, pois não só a densidade foi variável, bem como o número de perfilhos. Assim, para realizar a recomendação de manejo de uma pastagem, esta deve basear-se em um conjunto de variáveis como massa de forragem, altura do pasto, número de perfilhos e/ou densidade da forragem.

$\mathrm{Na}$ análise geral dos quatro períodos de utilização da pastagem (Figura 2), a massa de forragem, o número de perfilhos e a densidade da pastagem apresentaram comportamento quadrático, com ponto de máximo aos 42,55; 
47,25; e 53,52 dias, respectivamente. A variável massa de folhas verdes secas apresentou comportamento linear decrescente, ou seja, a cada dia de utilização da pastagem reduziu-se $15,7940 \mathrm{~kg} /$ ha de folhas verdes secas. A redução foi de 36,3; 64,7 e 82,8\% para cada período de 21 dias, entre agosto e novembro. Esses resultados seguem as observações de vários autores (Blaser, 1964; Stobbs, 1973; Lupatini, 1996) de que a porcentagem de folhas na estrutura da pastagem diminui com a maturidade das plantas.

Não foi encontrada interação significativa entre as doses de nitrogênio e os períodos da avaliação para taxa de acúmulo e massa de forragem parcial ( $\mathrm{P}>0,05)$ (Figura 3). A taxa de acúmulo de forragem sofreu aumentos lineares $(0,1873 \mathrm{~kg} / \mathrm{ha} / \mathrm{dia}$ de MS por $\mathrm{kg} / \mathrm{ha}$ de $\mathrm{N})$ com as doses crescentes de $\mathrm{N}$ empregadas (Figura 3a), demonstrando o potencial de resposta ao elemento pela espécie utilizada.

A taxa de acúmulo média diária foi de 27,6; 40,9; 57,8 e $68,8 \mathrm{~kg} / \mathrm{ha} /$ dia de matéria seca para as doses $0,75,150$ e $225 \mathrm{~kg} / \mathrm{ha}$ de N, respectivamente, proporcionando acúmulos na ordem de 48,2; 109,4; e 149,3\% superiores à não utilização de nitrogênio. A variável; a massa de forragem apresentou o mesmo comportamento da taxa de acúmulo, pois é o produto desta pelo número de dias de cada período (Figura 3b).

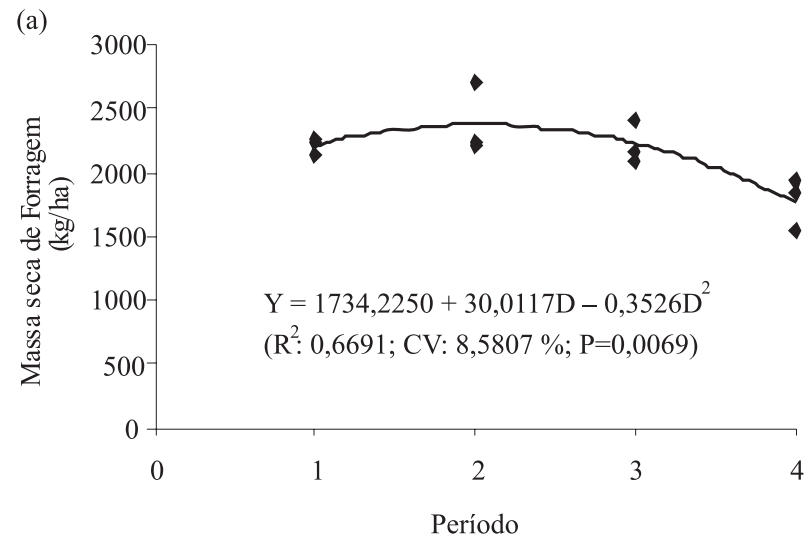

(c)

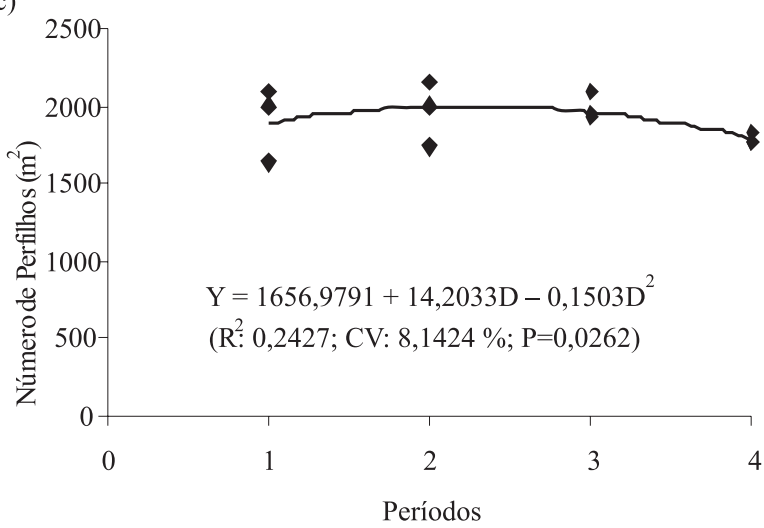

O efeito crescente da dose de nitrogênio sobre a taxa de crescimento das gramíneas é amplamente conhecido na literatura. Lemaire \& Chapman (1996) citam que a taxa de acúmulo é resultante da fixação de carbono durante o processo fotossintético, que se dá por meio da resposta fisiológica da planta ao nitrogênio, expressa pela taxa de aparecimento de folhas, pela expansão foliar e pela duração de vida da folha.

Lupatini et al. (1998), trabalhando com mistura de aveia mais azevém, usaram doses de 0,150 e $300 \mathrm{~kg} / \mathrm{ha}$ de $\mathrm{N}$ e também encontraram comportamento linear crescente para a taxa de acúmulo: para cada kg de nitrogênio aplicado aumentou 0,1955 kg/ha/dia de matéria seca produzida.

A produção total de MS é resultado do somatório da produção inicial e dos acúmulos diários durante todo o período experimental (Figura 4). Logo, a produção total de matéria seca comportou-se de maneira semelhante à taxa de acúmulo, apresentando resposta linear frente à fertilização nitrogenada, sendo que, para cada kg de nitrogênio, $15,839 \mathrm{~kg} / \mathrm{ha}$ de matéria seca foram resultantes. As produções médias totais de matéria seca observadas foram de 4203,2; 5696,8; 6851,3 e 7778,2 kg/ha de matéria seca para as doses 0, 75, 150 e $225 \mathrm{~kg} /$ ha de N, respectivamente. Assim, a
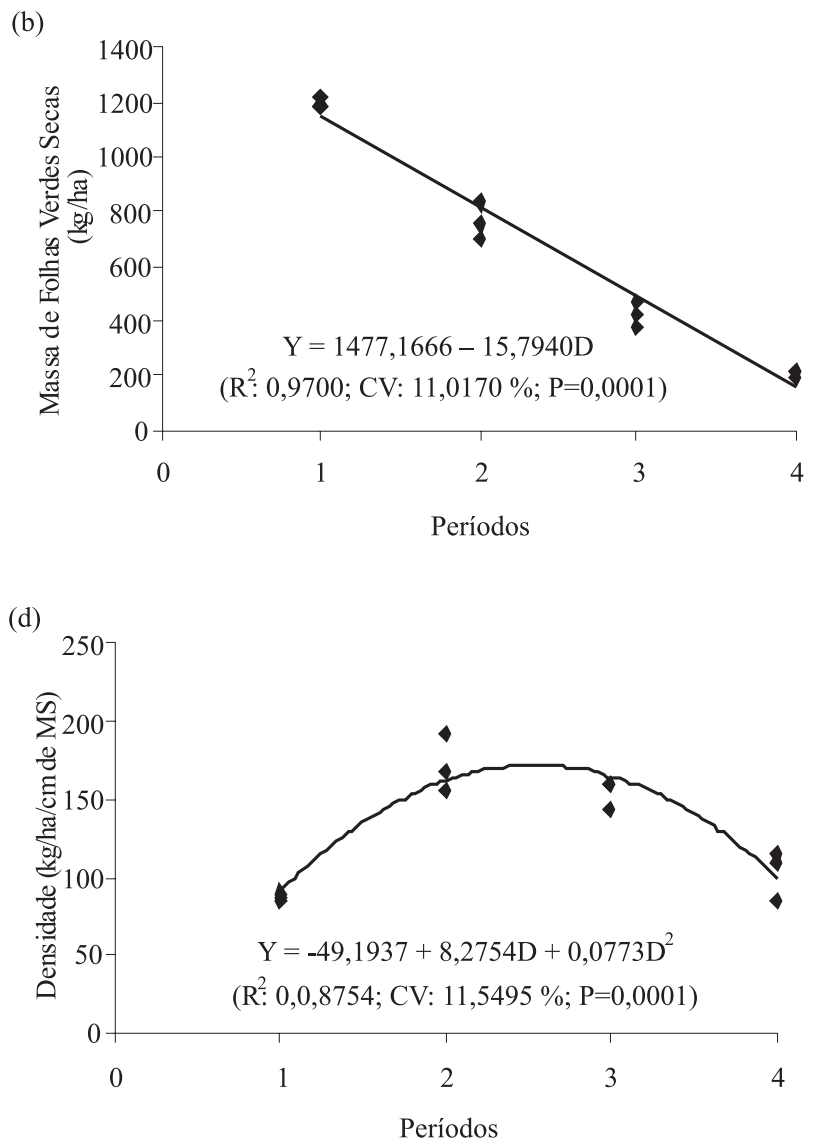

Figura 2 - Massa de forragem, massa de folhas verdes secas, número de perfilhos e densidade de forragem de uma pastagem de azevém sob lotação contínua de cordeiros. 
(a)

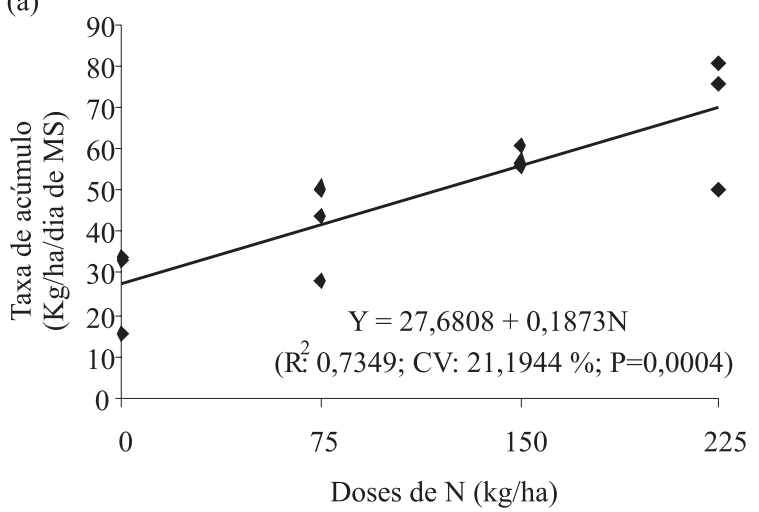

(b)

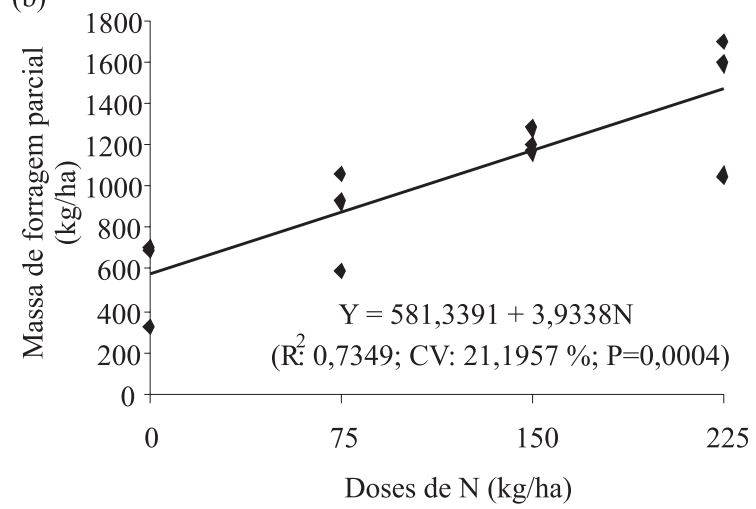

Figura 3 - Taxa de acúmulo e massa de forragem parcial de uma pastagem de azevém, sob lotação contínua de cordeiros e adubada com nitrogênio.

produção de forragem foi superior em 35,5; 63,0 e 85,1\% para as adubações com 75, 150 e $225 \mathrm{~kg} /$ ha de N, respectivamente, em relação às áreas sem fertilização.

Verifica-se que a relação folha:colmo apresentou comportamento linear crescente na ordem de 0,0010 para cada kg de nitrogênio aplicado no pasto de azevém (Figura 5a). O nitrogênio influencia diretamente as características morfogênicas das plantas forrageiras atuando diretamente na zona de alongamento e de divisão celular, aumentando o número de células, com isso favorecendo a taxa de expansão e o surgimento de folhas, o que, consequentemente proporcionou aumento na massa de folhas (Lustosa, 2002; Freitas, 2003) favorecendo o incremento na relação folha:colmo.

A relação folha:colmo apresentou redução de 0,0147 com o avanço no ciclo das plantas da pastagem (Figura 5b), o que está relacionado diretamente aos estágios fenológicos da planta passa durante o seu ciclo produtivo. Um dos motivos desta redução é a maturidade fisiológica da planta, ocorrendo o alongamento dos colmos. Para que ocorra o surgimento de uma folha esta deve percorrer o caminho dentro do pseudocolmo até a altura de inserção da folha

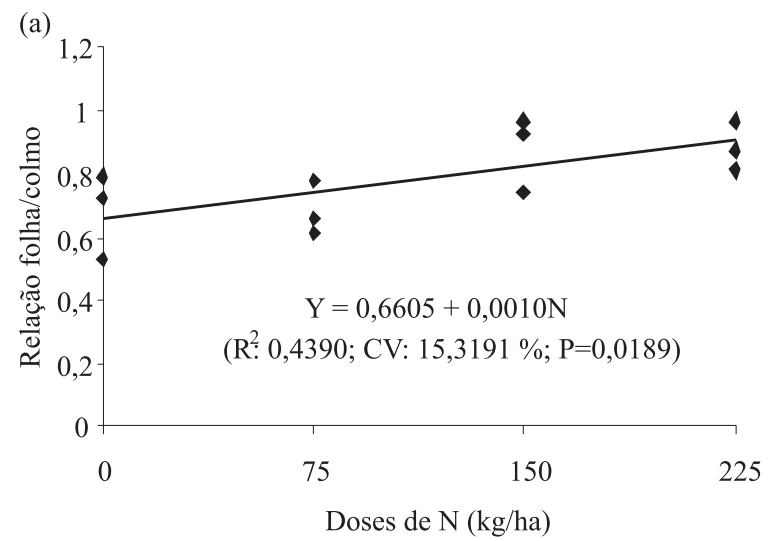

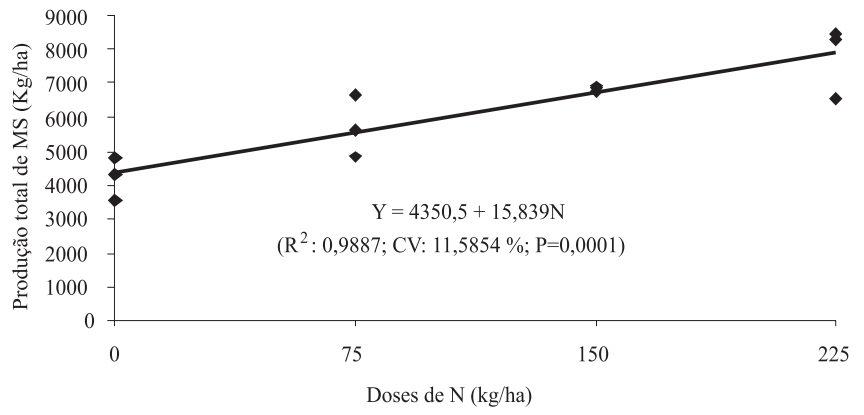

Figura 4 - Produção total de massa de forragem da pastagem de azevém sob lotação contínua de cordeiros e adubação nitrogenada.

completamente expandida, ou seja, a altura da bainha da folha antecessora (Duru et al., 1999).

Para os componentes das plantas, colmo, espiga e material senescente, não houve efeito da adubação nitrogenada, comvalores médios de 36,11; 13,18; e 23,55\%, respectivamente, para as doses de nitrogênio. No caso da participação do componente folha na massa de forragem, ocorreu efeito linear crescente do uso da fertilização, ou seja, para cada kg

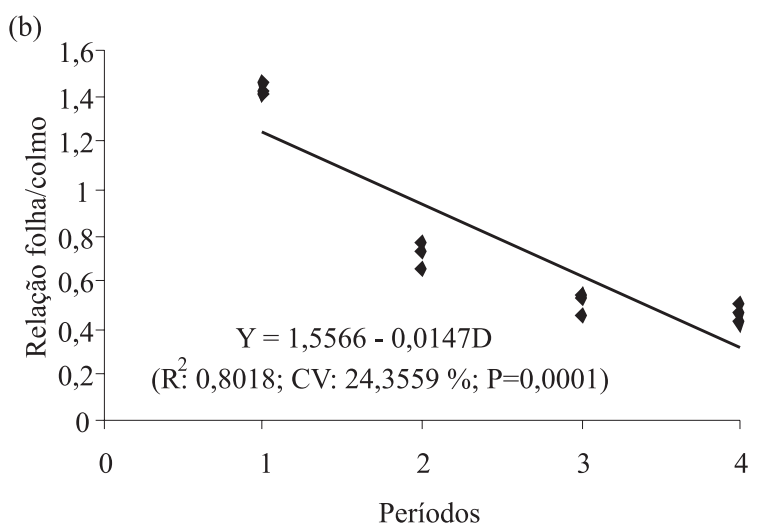

Figura 5 - Relação folha:colmo da pastagem de azevém sob lotação contínua de cordeiros e adubada com nitrogênio. 
de nitrogênio aplicado, aumentou a participação em 0,03\% de folhas na massa de forragem (Figura 6).

Há relação entre a porcentagem de folhas (Figura 6) e o número de perfilhos (Figura 1c) na pastagem, pois à medida que aumentou a porcentagem de folhas (21,8\% a mais para a dose 225 em relação à dose 0 de nitrogênio), o número de perfilhos também aumentou (38\% a mais para as mesmas doses). Cruz \& Boval (1999) confirmam que o aumento no número de perfilhos é ocasionado pela maior porcentagem de lâminas foliares (Figura 6).

Em relação aos períodos de utilização da pastagem (Figura 7), o componente colmo apresentou comportamento quadrático, com ponto de máxima participação na estrutura da pastagem aos 40,27 dias. Já a folha apresentou comportamento linear decrescente: à medida que avançou o ciclo do azevém, houve redução de $0,6986 \%$ deste componente na estrutura da pastagem. O inverso ocorreu com os componentes panícula e material senescente, que aumentaram em 0,4843 e 0,5109\%, respectivamente, com o avanço do ciclo.

Os teores de proteína bruta, fibra em detergente ácido e fibra em detergente neutro da pastagem não foram influenciados pelas doses de nitrogênio, apresentando
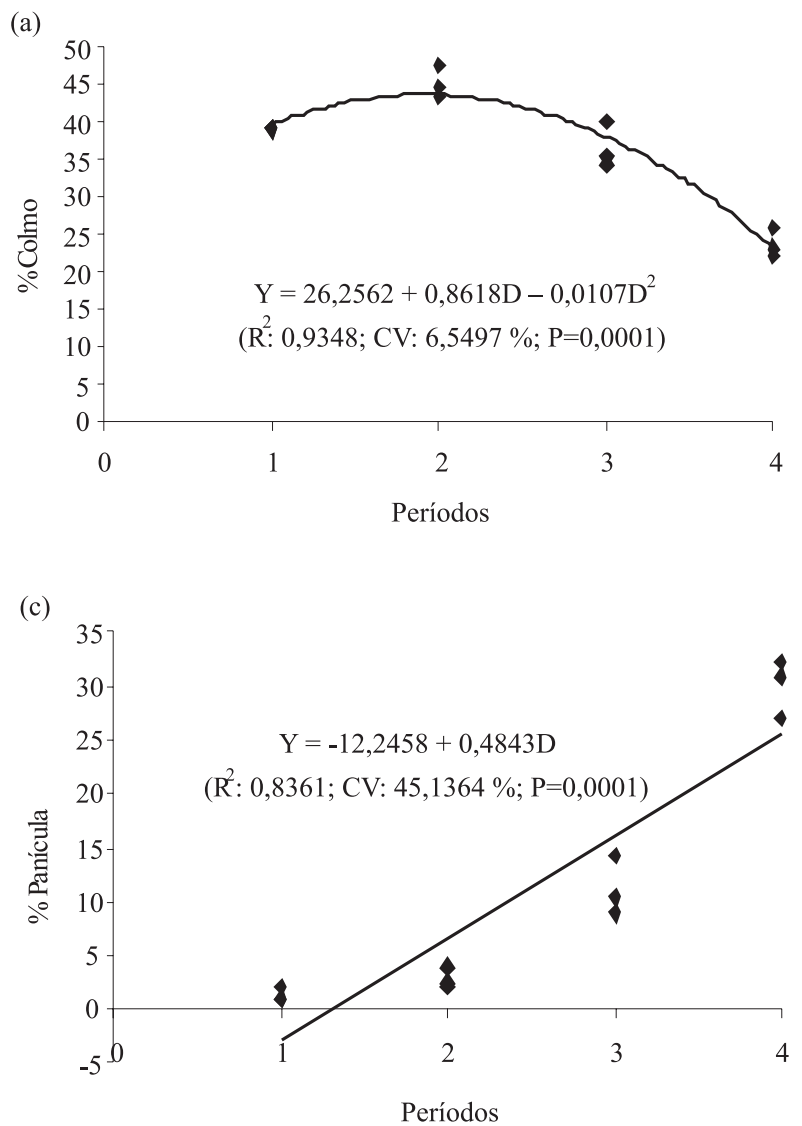

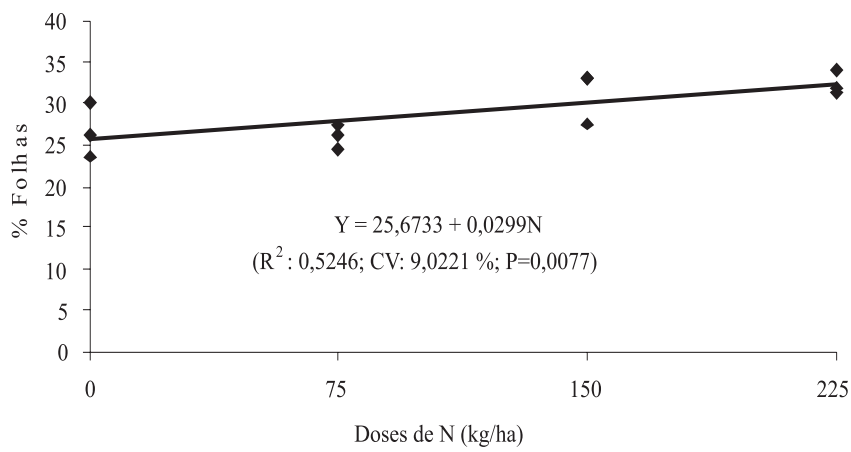

Figura 6 - Participação de folhas em uma pastagem de azevém sob lotação contínua de cordeiros adubada com nitrogênio.

valores médios de 21,62; 25,90 e 54,92\%, respectivamente. A não-diferença encontrada justifica-se pela técnica de colheita das amostras (hand plucking), simulando o pastejo dos animais (Burns et al., 1989). Os animais, quando em pastejo, exercem a seleção das partes mais nutritivas das plantas, apesar do uso do nitrogênio. Este aspecto é confirmado por Brâncio et al. (2003), que demonstraram que, mesmo em condições em que a percentagem de material morto é muito alta e a de lâminas foliares é baixa, o
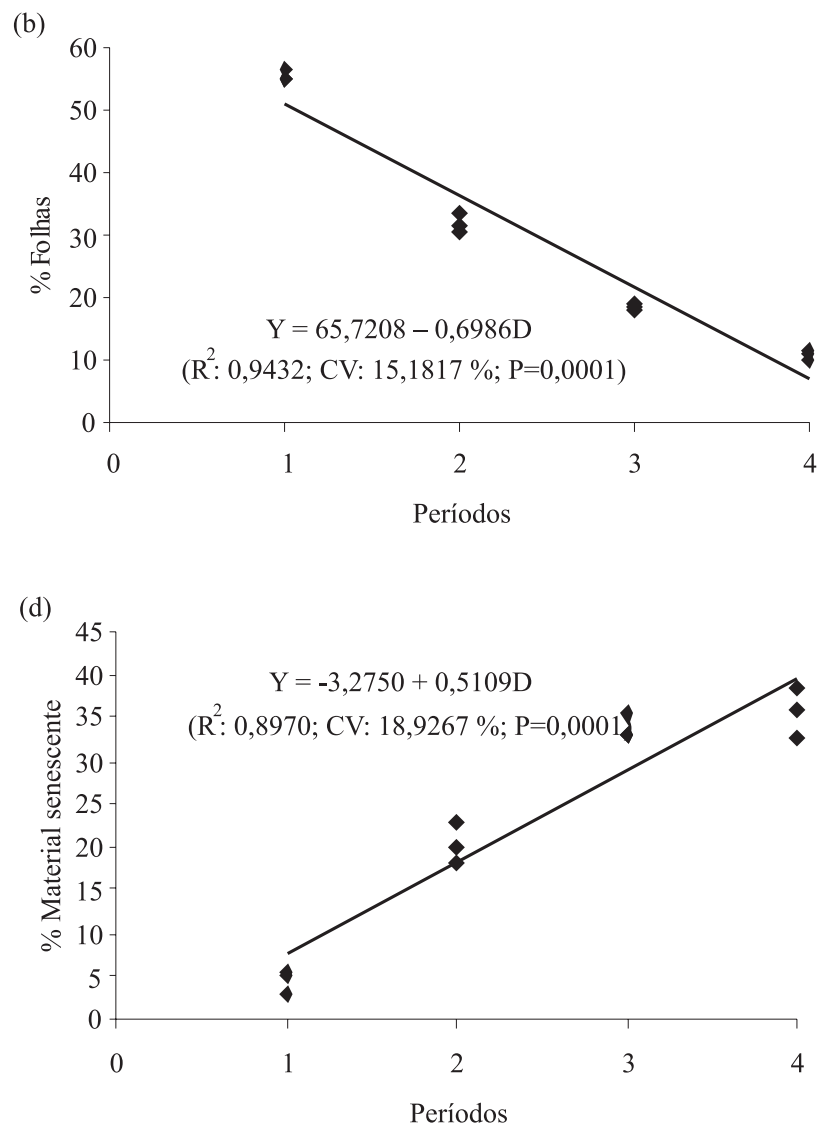

Figura 7 - Participação de colmo, folha, panícula e material senescente em uma pastagem de azevém sob lotação contínua de cordeiros em diversos períodos. 
ruminante consegue que mais de $80 \%$ de sua dieta seja composta de folhas.

Resultados contrários aos obtidos no presente experimento foi observado por Alvim \& Moojen (1984) e Lupatini et al. (1998), que encontraram aumentos lineares no teor de PB à medida que se elevaram as doses de nitrogênio. Difante et al. (2006), utilizando a mesma técnica de colheita das amostras, também não encontraram diferença entre as doses, com valor médio de 14,5\% proteína bruta. Segundo esses autores, o baixo valor justificou-se pelo excesso de chuva durante o período experimental. A fibra em detergente ácido e a fibra em detergente neutro são parâmetros importantes para se determinar a qualidade da forragem. Paterson et al. (1994) caracterizam uma espécie forrageira de alta qualidade quando apresentam valores inferiores a 30 e 60\% para fibra em detergente ácido e fibra em detergente neutro, respectivamente, o que leva à conclusão de que a pastagem se apresentava com boa qualidade nutricional aos cordeiros.

O teor de proteína bruta apresentou comportamento quadrático no decorrer dos períodos de avaliações, com ponto de mínimo aos 59,32 dias, obtendo-se valores de 23,30; 19,64; 20,57 e 21,77\% para o primeiro, segundo, terceiro e quarto períodos, respectivamente (Figura 8a).
Segundo Rocha et al. (2007), a estrutura da planta modifica-se durante seu ciclo, alterando as proporções entre lâminas foliares e colmos e, consequentemente, os nutrientes e os componentes acessíveis ao animal. Pedroso et al. (2004) verificaram teores elevados de proteína bruta no estádio vegetativo do azevém, diminuindo à medida que as plantas se aproximaram do florescimento, o que não foi obtido neste trabalho.

Os teores de fibra em detergente ácido e fibra em detergente neutro apresentaram aumento linear com o avanço do ciclo produtivo da pastagem, na ordem de 0,1200 e 0,5439\%, respectivamente, e os valores variaram de 20,87 e 39,05\% no primeiro período (20/8/2006 a 9/9/2006) para 28,76 e 75,89\% no quarto período (22/10/2006 a 11/11/2006) para fibra em detergente ácido e fibra em detergente neutro, respectivamente. Com o avanço do ciclo produtivo, a porção parede celular aumenta, elevando os valores de fibra em detergente ácido e fibra em detergente neutro (Van Soest, 1983). Isso é explicado pela menor quantidade de lâminas foliares e aumento na porcentagem de colmo e material senescente (Figura 6). Rocha et al. (2007) encontraram resultados semelhantes aos obtidos neste experimento.
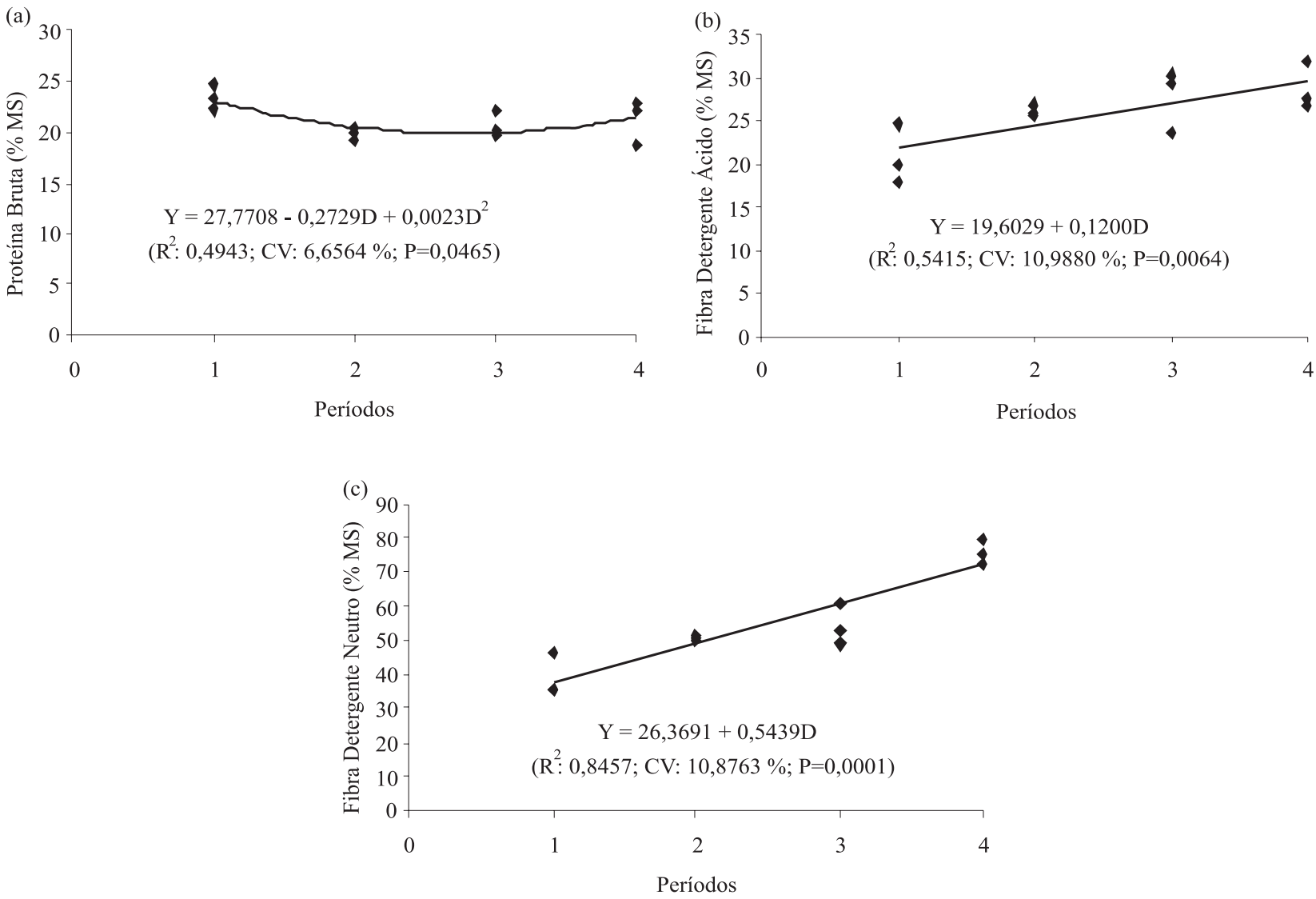

Figura 8 - Teores de proteína bruta, fibra detergente ácido e fibra detergente neutro da forragem colhida por simulação de pastejo em uma pastagem de azevém sob lotação contínua de cordeiros de corte. 


\section{Conclusões}

O aumento na dose de nitrogênio proporciona maior taxa de acúmulo e produção total de massa de forragem. A qualidade da massa de forragem não difere entre as doses de nitrogênio, quando selecionada pelos animais. O avanço no estádio fenológico do azevém, com o suceder dos ciclos, reduz a participação de folhas na massa de forragem, independentemente da dose de nitrogênio aplicada.

\section{Referências}

ALViM, M.J.; MOOJEN, E.L. Efeitos de fontes e níveis de nitrogênio e práticas de manejo sobre a produção e qualidade da forragem de azevém anual. Revista da Sociedade Brasileira de Zootecnia, v.13, n.2, p.243-253, 1984.

ASSMANN, A.; PELISSARI, A.; MORAES, A. et al. Produção de gado de corte e acúmulo de matéria seca em sistema de integração lavoura-pecuária em presença e ausência de trevo branco e nitrogênio. Revista Brasileira de Zootecnia, v.33, n.1, p.37-44, 2004.

ASSOCIATION OF OFFICIAL ANALYTICAL CHEMISTS AOAC. Official methods of analysis. 16.ed. Washington, D.C., 1995. 2000p.

BIRCHAM, J.S. Herbage growth and utilization under continuous stocking management. 1981. 384f. Thesis (Ph.D in Computer Science) - University of Edinburgh, Edinburgh.

BLASER, R.E. Symposium on forage utilization: effects of fertility levels and stage of maturity on forage nutritive value. Journal of Animal Science, v.23, p.246-253, 1964.

BRÂNCIO, A.P.; NASCIMENTO JR., D.; EUCLIDES, V.P.B. et al. Avaliação de três cultivares de Panicum maximum Jacq. sob pastejo: composição da dieta, consumo de matéria seca e ganho de peso animal. Revista Brasileira de Zootecnia, v.32, n.5, p.1037-1044, 2003

BURMS, J.C.; LIPPKE, H.; FISHER, D.S. The relationship of herbage mass and characteristics to animal responses in grazing experiments. In: MARTEN, G.C. (Ed.) Grazing research: design, methodology and analysis. Madison: CSSA, 1989. p.7-20.

CAMPBELL, A.G. Grazed pasture parameters. I. Pasture dry matter production and availability in a stocking rate and grazing management experiment with dairy cows. Journal of Agricultural Science, v.67, n.2, p.199-210, 1966.

CARVALHO, P.C.F.; MARÇAL, G.K.; RIBEIRO FILHO, H.M.N. et al. Pastagens altas podem limitar o consumo dos animais. In: REUNIÃO ANUAL DA SOCIEDADE BRASILEIRA DE ZOOTECNIA, 38., 2001, Piracicaba. Anais... Piracicaba: SBZ, 2001. p.265-268.

COMISSÃO DE FERTILIDADE DO SOLO - RS/SC (Passo Fundo, $R S)$. Recomendações de adubação e calagem para os Estados do Rio Grande do Sul e Santa Catarina. 3.ed. Passo Fundo: Sociedade Brasileira de Ciência do Solo/EmbrapaCNPT, 1995. 223p.

CRUZ, P.; BOVAL, M. Effect of nitrogen on some morphogenetical traits of temperte and tropical perennial forage grasses. In: INTERNATIONAL SYMPOSIUM "GRASSLAND ECOPHSIOLOGY AND GRAZING ECOLOGY”, 1999, Curitiba. Anais... Curitiba: UFPR, 1999. p.134-150.

DIFANTE, G.S.; MARCHEZAN, E.; VILLA, S.C.C. et al. Produção de novilhos de corte com suplementação em pastagem de azevém submetida a doses de nitrogênio. Revista Brasileira de Zootecnia, v.35, n.3, p.1107-1113, 2006 (supl.).

DURU, M.; DUCROCQ, H.; FEUILLERAC, E. Effect of defoliation regime and nitrogen supply on the phyllochron of cocksfoot. Académie des Sciences, v.311, p.717-722, 1999.
EMPRESA BRASILEIRA DE PESQUISA AGROPECUÁRIA EMBRAPA. Centro Nacional de Pesquisa do Solo - CNPS. Sistema Brasileiro de Classificação de solos. Brasília: EMBRAPA, 2006. 306p.

FRANK, A.B.; HOFMAN, L. Light quality and stem numbers in coolseason forage grasses. Crop Science, v.34. p.468-473. 1994

FREITAS, T.M.S. Dinâmica da produção de forragem, comportamento ingestivo e produção de ovelhas Ile de France em pastagem de azevém anual (Lolium multiflorum Lam.) em resposta a doses de nitrogênio. 2003. $114 \mathrm{f}$ Dissertação (Mestrado em Zootecnia) - Universidade Federal do Rio Grande do Sul, Porto Alegre.

GARCEZ NETO, A.F.; NASCIMENTO JR., D.; REGAZZI, A.J. et al. Respostas morfogênicas e estruturais de Panicum maximum cv. Mombaça sob diferentes níveis de adubação nitrogenada e alturas de corte. Revista Brasileira de Zootecnia, v.31, n.5, p.1890-1900, 2002.

GARDNER, A.L. Técnicas de pesquisa em pastagem e aplicabilidade de resultados em sistemas de produção. Brasília: IICA/EMBRAPA_CNPGL, 1986. 197p. (IICA, Série publicações Miscelâneas, 634).

GASTAL, F.; BÉLANGER, G.; LEMAIRE, G. A model of the leaf extension rate of tall fescue in response to nitrogen and temperature. Annals of Botany, v.70, p.437-442, 1992.

HODGSON, J. Grazing management: science into practice. Longman Handbooks in Agriculture. New York: John Wiley \& Sons, 1990. 203p.

LEMAIRE, G.; GASTAL, F. Nitrogen uptake and distribution in plant canopies. In: LEMAIRE, G. (Ed.) Diagnosis of the nitrogen status in crops. Heidelberg: Springer-Verlag, 1997, p.3-43.

LEMAIRE, G. Physiologie des graminées fourragéres: croissance. Technology Agriculture, n.220, p.3-18, 1991.

LEMAIRE, G.; CHAPMAN, D. Tissue flows in grazed plant communities. In: HODGSON, J.; ILLIUS, A.W. (Eds.) The ecology and management of grazing systems. Oxon: CABI, 1996. p.3-36.

LEMAIRE, G.; AGNUSDEI, M. Leaf tissue turn-over and efficiency of herbage utilization. In: INTERNATIONAL SYMPOSIUM "GRASSLAND ECOPHSIOLOGY AND GRAZING ECOLOGY", 1999, Curitiba. Anais... Curitiba: UFPR, 1999. p.165-186.

LUPATINi, G.C. Produção animal em milheto (Pennisetum americanum (L.) Leeke) submetido a níveis de adubação nitrogenada. 1996. 126f. Dissertação (Mestrado em Zootecnia) - Universidade Federal de Santa Maria, Santa Maria.

LUPATINI, G.C.; RESTLE, J.; CERETA, M. et al. Avaliação da mistura de aveia preta e azevém sob pastejo submetida a níveis de nitrogênio. Pesquisa Agropecuária Brasileira, v.33, n.11, p.1939-1943, 1998.

LUSTOSA, S.B.C. Características estruturais e morfogênicas de azevém anual em resposta ao nitrogênio. 2002. 64f. Tese (Doutorado em Agronomia) - Universidade Federal do Paraná, Curitiba.

MANZANTI, A.; LEMAIRE, G. Effect of nitrogen fertilization on herbage production of tall fescue swards continuously grazed by sheep. 2. Consumption and efficiency of herbage utilization. Grass and Forage Science, v.49, p.352-359, 1994.

MAZZANTI, A.; LEMAIRE, G.; GASTAL, F. The effect of nitrogen fertilization upon the herbage production of tall fescue swards continuously grazed with sheep. 1. Herbage growth dynamics. Grass and Forage Science, v.49, p.111-120, 1994.

MONTEITH, J.L. Climate and efficiency of crop production in Britain. Philosophical Transaction of Royal Society, series B 281, p.277-294, 1977.

MOOT, G.O.; LUCAS, H.L. The design conduct and interpretation of grazing trials on cultivated and improved pastures. In: INTERNATIONAL GRASSLAND CONGRESS. 6., 1952, Pensylvania. Proceedings... Pensylvania: State College, 1952. p.1380-1395. 
MORAES, A.; MOOJEN, E.L.; MARASCHIN, G.E. Comparação de métodos de estimativa de taxas de crescimento em uma pastagem submetida a diferentes pressões de pastejo. In: REUNIÃO ANUAL DA SOCIEDADE BRASILEIRA DE ZOOTECniA, 27., 1990, Campinas. Anais... Piracicaba: FEALQ, 1990. p.332.

MORÓN, A. El ciclo del nitrogeno en el sistema suelo-plantaanimal. Seminario de actualización, técnica, INIA la Estanzuela, Uruguai, 1994. p.64. (Serie Técnica, 51).

MOTT, G.O.; QUINN, L.R.; BISSCHOFF, W.V.A. The retention of nitrogen in a soil-plant-animal system in guinea grass (Pannicum maximum) pastures in Brazil. In: PROCEEDINGS OF THE INTERNATIONAL GRASSLAND CONGRESS, 1970, Queensland. Anais... Queensland: University of Queensland Press, 1970. p.414-416.

NABINGER, C. Princípios da exploração intensiva de pastagens. In: SIMPÓSIO SOBRE MANEJO DA PASTAGEM, 13., 1996, Piracicaba. Anais... Piracicaba: FEALQ, 1996. p.15-95.

PATERSON, J.A.; BELYEA, R.L.; BOWMAN, J.P. et al. The impact of forage quality and supplementation regimen on ruminant animal intake and performance. In: FAHEY JR., G.C. (Ed.). Forage quality, evaluation, and utilization. Madison: ASA, 1994. p.59-114.

PEDROSO, C.E.S.; MEDEIROS, R.B.; SILVA, M.A. et al. Comportamento de ovinos em gestação e lactação sob pastejo em diferentes estádios fenológicos de azevém anual. Revista Brasileira de Zootecnia, v.33, n.5, p.1340-1344, 2004.

PONTES, L.; NABINGER, C.; CARVALHO, P.C.F. et al. Variáveis morfogênicas e estruturais de azevém anual (Lolium multiflorum Lam.) manejado em diferentes alturas. Revista Brasileira de Zootecnia, v.32, n.4, p.814-820, 2003.
ROCHA, M.G.; PEREIRA, L.E.T.; SCARAVELLI, L.F.B. et al Produção e qualidade de forragem da mistura de aveia e azevém sob dois métodos de estabelecimento. Revista Brasileira de Zootecnia, v.36, n.1, p.7-15, 2007.

ROMAN, J.; ROCHA, M.G.; PIRES, C.C. et al. Comportamento ingestivo e desempenho de ovinos em pastagem de azevém anual (Lolium multiflorum Lam.) com diferentes massas de forragem. Revista Brasileira de Zootecnia, v.36, n.4, p.780-788, 2007.

SANTOS, M.E.R.; FONSECA, D.M., BALBINO, E.M. Capimbraquiária diferido e adubado com nitrogênio: produção e características da forragem. Revista Brasileira de Zootecnia, v.38, n.4, p.650-656, 2009.

SOARES, A.B.; RESTLE, J. Produção animal e qualidade de forragem de pastagem de triticale e azevém submetida a doses de adubação nitrogenada. Revista Brasileira de Zootecnia, v.31, n.2, p.908-917, 2002.

STATISTICAL ANALISYS SYSTEMS - SAS. User's guide: statistics. Version 6, Cary: 1997, v.2. 1052p.

STOBBS, T.H. The effect of plant structure on the intake of tropical pastures. II. Differences in sward structure, nutritive value and bite size of animals grazing Setaria anceps and Chloris gayana at various stages of growth. Australian Journal of Agricultural Research, v.24, n.6, p.821-829, 1973.

VAN SOEST, P.J. Nutritional ecology of the ruminant. Corvalis: Cornell University, 1983. p.88.

VAN SOEST, P.J.; ROBERTSON, J.B.; LEWIS B.A. Methods for dietary fiber, neutral detergent fiber, and nonstarch polysaccharides in relation to animal nutrition. Journal of Dairy Science, v.74, n.10, p.3583-3597, 1991.

WHITEHEAD, D.C. Grassland nitrogen. Wallingford: CAB International, 1995. p.397. 